LETTERS

\section{A zebrafish model exemplifies the long preclinical period of motor neuron disease}

To the Editor, The article 'Amyotrophic lateral sclerosis: a long preclinical period?" is an interesting and thoughtprovoking review. ${ }^{1}$ We commend the authors for raising the profile of early embryonic and preclinical stages that are currently poorly explored in amyotrophic lateral sclerosis (ALS) research.

In relation to these concepts, we would like to highlight recent, important work on a zebrafish model of ALS that contributes to the concept of preclinical change. Specifically, we have developed a sod1 zebrafish model of ALS/motor neuron disease (MND) and demonstrated that zebrafish, like mice and humans, show hallmark features of ALS, suggesting that the zebrafish provides an excellent model system to study motor neuron disease. ${ }^{2}$ Additionally, the transparency and ex vivo development of embryos enables one to trace early embryonic changes in disease pathogenesis. As a follow-up to the original study, our further studies have established that the temporal changes in neuronal populations and circuitry were evident from the earliest embryonic stages to adulthood. ${ }^{3}$ Using the sod1 zebrafish transgenic model carrying a fluorescent hsp70-DsRed reporter of neuronal stress, we demonstrated that different neurons at successive stages of the disease show evidence of neuronal stress detected by the activation of the heat shock response. The earliest neurons to exhibit neuronal stress were the inhibitory interneurons, with almost $50 \%$ of the glycinergic interneurons in the spinal cord showing neuronal stress in early zebrafish embryos at $24 \mathrm{~h}$ postfertilisation. ${ }^{3}$ This stress is followed by a reduction in the glycinergic input to motor neurons as evidenced by a reduced frequency of spontaneous glycinergic miniature postsynaptic currents (mPSCs) in motor neurons of sod1 mutant embryos. ${ }^{3}$ What was most interesting was that this did not immediately activate a stress response in motor neurons, as all the motor neurons in the spinal cord did not exhibit DsRed expression at this stage. However, by adult stages (6-month-old zebrafish), the cholinergic motor neurons started showing neuronal stress. ${ }^{3}$ The stressed motor neurons additionally showed denervation changes at the neuromuscular junction (NMJ). Indeed, by examining DsRed expression in motor
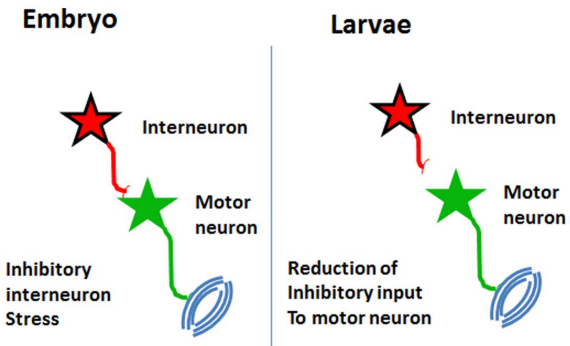

Adult

24hpf or earlier

$96 \mathrm{hpf}$

Figure 1 Chronic preclinical changes in sod1 zebrafish model of ALS. As early as $24 \mathrm{hpf}$ (embryos), the zebrafish embryos show neuronal stress predominantly in the inhibitory interneurons of the spinal cord. By $96 \mathrm{hpf}$ (larvae), a reduction in inhibitory input to motor neurons is observed, suggesting lack of sufficient innervation by inhibitory interneurons on the motor neurons and/or denervation of existing inhibitory synapses on motor neurons. Interestingly, the motor neurons do not show neuronal stress at this time. However, over a span of a few months (adults), motor neurons in the adult spinal cord show neuronal stress and the synapses of stressed motor neurons show clear abnormalities at the neuromuscular junction (NMJ). Thus, in the mutant sod1 zebrafish model, gradual and incremental changes occur within the neural circuit to finally impact on motor neurons and their accompanying neuromuscular connectivity. hpf, hours postfertilisation.

neuron axons, we found that NMJ denervation occurred exclusively in the synapses arising from stressed cells. While the delay in the onset of stress response in the motor neurons may reflect the increased threshold for activation of the stress response in motor neurons, ${ }^{4}$ the fact that stress was induced in the motor neurons in the symptomatic stages of the disease further supports the concept that research on extramotor neuronal involvement during the preclinical period of ALS is warranted.

Additionally, we showed that riluzole, the only drug approved to ameliorate the disease course in ALS, reduces this early neuronal stress at the embryonic stage, which supports the concept that the neuronal stress response model is a valid way to detect early neuronal changes during disease pathogenesis in $\mathrm{ALS}^{3}$ (figure 1).

The review from Eisen and colleagues combined with our data has key implications for the development of therapies for ALS as it becomes crucial to know how early in the disease intervention needs to be initiated to enable a significant impact on disease progression. If late-stage intervention as currently practised in the clinic provides minimal benefit, it becomes even more important that the focus be shifted towards earlier diagnosis and treatment. Additionally, molecular targets for intervention change at different stages of disease and hence need to be hierarchically categorised and prioritised for drug discovery and development.
Tennore M Ramesh, ${ }^{1}$ Pamela J Shaw, ${ }^{1}$ Jonathan McDearmid ${ }^{2}$

${ }^{1}$ Department of Neuroscience, Sheffield Institute for Translational Neuroscience, University of Sheffield, Sheffield, UK

${ }^{2}$ Department of Biology, University of Leicester, Leicester, UK

Correspondence to Dr Tennore M Ramesh, Department of Neuroscience, Sheffield Institute for Translational Neuroscience, University of Sheffield, 385a Glossop Road, Sheffield S10 2HQ, UK; t.ramesh@sheffield.ac.uk

Contributors TMR prepared the initial draft of the letter, and PJS and JM edited and refined the letter.

Competing interests None.

Provenance and peer review Not commissioned; externally peer reviewed.

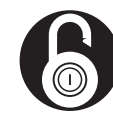

\section{OPEN ACCESS}

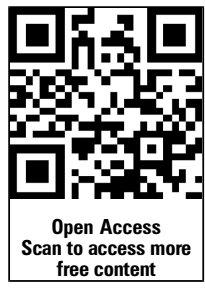

Open Access This is an Open Access article distributed in accordance with the Creative Commons Attribution Non Commercial (CC BY-NC 4.0) license, which permits others to distribute, remix, adapt, build upon this work non-commercially, and license their derivative works on different terms, provided the original work is properly cited and the use is non-commercial. See: http:// creativecommons.org/licenses/by-nc/4.0/

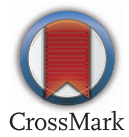

To cite Ramesh TM, Shaw PJ, McDearmid J. J Neurol Neurosurg Psychiatry 2014;85:1288-1289. 
Received 11 April 2014

Accepted 2 June 2014

Published Online First 26 June 2014

\section{SLinked}

- http://dx.doi.org/10.1136/jnnp-2013-307135

- http://dx.doi.org/10.1136/jnnp-2014-308588

J Neurol Neurosurg Psychiatry 2014;85:1288-1289.

doi:10.1136/jnnp-2014-308288

\section{REFERENCES}

1 Eisen A, Kiernan M, Mitsumoto H, et al. Amyotrophic lateral sclerosis: a long preclinical period? I Neurol Neurosurg Psychiatry 2014;85:1232-8.

2 Ramesh T, Lyon AN, Pineda RH, et al. A genetic model of amyotrophic lateral sclerosis in zebrafish displays phenotypic hallmarks of motoneuron disease. Dis Model Mech 2010;3:652-62.

3 McGown A, McDearmid JR, Panagiotaki N, et al. Early interneuron dysfunction in ALS: insights from a mutant sod1 zebrafish model. Ann Neurol 2013;73:246-58.

4 Batulan Z, Shinder GA, Minotti S, et al. High threshold for induction of the stress response in motor neurons is associated with failure to activate HSF1. J Neurosci 2003;23:5789-98. 